\title{
DE ZELFSTANDIGHEID DER EILANDGEBIEDEN IN DE NEDERLANDSE ANTILLEN
}

$$
\text { DOOR }
$$

\section{Mr W. H. van Helsdingen}

Zullen in de staatkundige geschiedenis der Nederlandse Antillen 14 Maart en 6 September $195 I$ als historische data worden herdacht? Zal misschien de toekomst meer dan het heden de betekenis erkennen van de inwerkingtreding van de Eilandenregeling en van de overdracht van de eerste dienst (Dienst van Openbare Werken)?

$\mathrm{Al}$ wordt de draagwijdte van de getroffen maatregelen nog lang niet in volle omvang begrepen, er behoeft niet getwijfeld te worden aan het grote belang van de Eilandenregeling Nederlandse Antillen, waarbij aan Aruba, Bonaire, Curaçao en de Bovenwindse eilanden een zeer grote mate van zelfstandigheid binnen het verband van de Nederlandse Antillen is verleend. Alvorens de strekking van bedoelde regeling weer te geven en de aan de uitvoering verbonden moeilijkheden, worde in het kort achtergrond en voorgeschiedenis en de totstandkoming van de Eilandenregeling belicht.

Hoewel tevoren reeds van enige animositeit tussen verschillende eilanden sprake is geweest, kwam toch eerst na de oorlog de wens van Aruba tot uiting zich van de overige eilanden van de Nederlandse Antillen af te scheiden en in rechtstreekse verbinding met Nederland te komen staan. De economische ontwikkeling van Aruba had door de vestiging van de raffinaderij van de Lago Oil and Transport Company in 1924 een grote vlucht genomen. Men meende de eigen zaken geheel zelfstandig te kunnen regelen en was de afhankelijkheid van het centrale, op Curaçao gevestigde gezag moe. $\mathrm{Nu}$ bestond inderdaad in de Nederlandse Antillen een streng gecentraliseerde bestuursvorm. Voor de ambtenaren op de eilanden buiten Curaçao bestond geen noe-

$$
-193-
$$


menswaarde vrijheid van bewegen, zelfs nauwelijks in zaken van louter plaatselijke aard, laat staan, dat de bevolkingen der eilanden noemenswaard invloed op de gang van zaken vermochten uit te oefenen.

Weliswaar opende het Regeringsreglement van 1865 reeds de mogelijkheid voor een zekere decentralisatie van bestuur en wetgeving, doch hetgeen in die richting verwezenlijkt is, was slechts van elementaire aard. In 1922 werd door de Minister van Koloniën een commissie benoemd om advies uit te brengen o.m. hoe de Regeringsreglementen waren te wijzigen ten aanzien van de instelling van plaatselijke besturen. Het rapport van deze Commissie-StaAl heeft mede er toe geleid, dat bij de Staatsregeling van 1936 aan de landsverordeningwetgever de bevoegdheid werd gegeven werkelijk autonome gemeenschappen in het leven te roepen. Na herhaald aandringen van de Staten werd in December 1942 door de Gouverneur een commissie ,ter bestudering van staatkundige aangelegenheden" ingesteld onder voorzitterschap van Prof. Mr A. S. Oppenheim om o.m. bedoelde bepalingen uit te werken. Haar in Februari 1944 ingediend rapport ging vergezeld van een ontwerp-landsverordening, hetwelk echter met verscheidene wijzigingen ,waarvan sommige zelfs van principiële aard", pas in Februari 1946 bij de Staten werd voorgebracht. Daar ondervond het zoveel tegenkanting, dat het in October 1948 werd ingetrokken.

Deze gang van zaken is te betreuren. Indien het ontwerpOPPENHEIM - hoe dan ook gewijzigd - op korte termijn het Publicatieblad had kunnen bereiken, zou reeds jarenlang een goede leerschool zijn doorlopen. Omdat de gecentraliseerde bestuursvorm onverkort gehandhaafd bleef, werd de roep van Aruba om afscheiding van Curaçao veelvuldiger en luider gehoord. Bij de wijziging van de Staatsregeling van 1948 - welke de bedoeling had aan de in de Nederlandse Antillen tot uiting gekomen staatkundige wensen tegemoet te komen zover dat binnen het raam van de bestaande grondwet mogelijk was - werd een poging tot verzoening gedaan door aan Aruba evenveel zetels in de Staten toe te kennen als aan Curaçao, nl. aan elk 8, aan Bonaire 2 en aan ieder der Bovenwindse Eilanden 1. De Regering heeft dit advies van de meerderheid van de Staten overgenomen, in afwijking van haar eigen voorstel (Curaçao 11 zetels, Aruba 7, Bonaire 2, de Bovenwindse Eilanden tezamen 1) en tegen het voorstel van een minderheid welke de 18 zetels voor Aruba en Curaçao door toepassing van het evenredig kiesstelsel wilde doen verdelen. 
Nog voordat de wijziging van de Staatsregeling in werking was getreden, bleek dat Aruba met de zetelverdeling alleen niet tevreden gesteld kon worden, en dat het zijn verder strekkende verlangens niet prijs gaf. Het bleef aandringen op een zelfstandige status, los van Curaçao, rechtstreeks met Nederland verbonden. Het wist gedaan te krijgen dat een motie tot onderzoek in die geest op de Conferentie Nederland-Suriname-Nederlandse Antillen werd aangenomen. Het gevolg was de instelling van een commissie (commissie Aruba-Curaçao) in Juni 1948 om gegevens te verzamelen, waaruit zou kunnen worden besloten in hoeverre de verlangens van Aruba zouden kunnen worden verwezenlijkt.

Reeds ruim een maand later bracht de commissie haar rapport uit.

Bleek de bovenvermelde verzoeningspoging de Arubaanse verlangens niet te bevredigen, erger was, dat de tot stand gebrachte zetelverdeling 8-8 een negatief resultaat had. Reeds spoedig, reeds vóór de nodig geworden verkiezingen, werd de kritiek daarop luider; nu van de zijde van Curaçao, dat zich te kort gedaan achtte in vergelijking met het in zielen-aantal kleinere Aruba.

De Regering verklaarde echter uitdrukkelijk bij monde van Minister vaN SCHAIK, dat de zetelverdeling vóór de op handen zijnde verkiezingen van 1949 niet zou worden gewijzigd. Dit is ook niet geschied ${ }^{\mathbf{1}}$ ).

De Regering was van oordeel dat door zetelverdeling alleen geen bevredigende oplossing zou kunnen worden bereikt. Zij wilde de zetelverdeling koppelen aan vier andere maatregelen:

$I$ een gemitigeerd twee-kamerstelsel

2 een beroepsrecht op de Kroon

3 vastlegging van de hoofdbeginselen voor een Eilandenregeling in de Landsregeling

4 gelijktijdige inwerkingtreding van de nieuwe zetelverdeling en van de Eilandenregeling.

$I$ De Staten zouden komen te bestaan uit twee kamers: een op grondslag van evenredige vertegenwoordiging gekozen Volksraad, en een Federale Raad waarin Curaçao en Aruba elk vijf zetels zouden bezetten, Bonaire twee en ieder der Bovenwindse Eilanden één. De Federale Raad zou alleen fungeren als vijf of

1) Toen bij de Interimregeling van 1950 de zetelverdeling gewijzigd werd, beschuldigden enkele Arubanen Minister vaN SCHAIK van woordbreuk. Geheel ten onrechte; op de thans door mij gecursiveerde woorden in bovenstaande verklaring komt het juist aan. 
meer leden dier Raad het verzoek zouden doen een door de Volksraad goedgekeurde ontwerp-landsverordening in behandeling te nemen. Verdere details worden thans achterwege gelaten.

Dit voorstel is in de Antillen niet aanvaard, ja, niet eens behoorlijk bestudeerd. De leden van Aruba en van de Bovenwindse Eilanden meenden blijkbaar de bestaande zetelverdeling te kunnen behouden door zich tegen elk wijzigingsvoorstel te verzetten.

2 De Regering wilde de kleinere eilanden een garantie geven, dat zij niet zouden worden ,overheerst" door andere eilanden, door vijf of meer leden van de Staten de bevoegdheid te geven in beroep te komen bij de Kroon, indien naar hun mening ten gevolge van een verordening de belangen van een of meer eilandgebieden ernstig zouden worden geschaad.

De Staten verklaarden zich unaniem tegen dit voorstel, nadat het met een etiket ,,kolonialisme” was voorzien. Alsof Nederland er genoegen in zou hebben zich in de onderlinge kwesties overzee te mengen! Zij stelden daar een voor de Regering onaanvaardbaar voorstel tegenover, dat een destructief karakter had. De Regering heeft tenslotte in art. 100 Landsregeling de mogelijkheid geopend dat bij algemene maatregel van bestuur een instantie wordt aangewezen, wier goedkeuring vereist is alvorens een door de Staten goedgekeurde landsverordening in werking kan treden.

De afwijkende houding van de Arubanen ook ten aanzien van dit punt had alleen ten doel de 8-8 verhouding te behouden. Achteraf, nu dit hun niet gelukt is, laten zij geen gelegenheid ongebruikt op instelling van een beroepsinstantie aan te dringen. In de Staten stuiten zij echter op weerstand.

3 De hoofdbeginselen van de Eilandenregeling zijn in de Landsregeling verankerd. Wij komen daarop nader terug.

4 De gelijktijdige inwerkingtreding van de nieuwe zetelverdeling en van de Eilandenregeling is bereikt: op 21 Februari 1951 traden de in December 1950 nieuw verkozen Staten op en op 14 Maart 1951 trad de algemene maatregel van bestuur, houdende de Eilandenregeling in werking.

Waarom - zo zal men vragen - is de Eilandenregeling bij algemene maatregel van bestuur vastgesteld? Had dit niet kunnen geschieden bij een landsverordening, zoals ook in 1946 door de Staten een eilandsverordening is voorgebracht? Het antwoord is tweeledig: enerzijds was er niet voldoende onderling vertrou- 
wen, dat bij een landsverordening aan de belangen van ieder eiland voldoende recht zou worden gedaan, anderzijds kon wederom ter bevordering van de goede onderlinge verstandhouding - het hoger toezicht in bepaalde gevallen in plaats van aan de landsregering aan de Kroon worden voorbehouden. Niettemin bestaat krachtens artikel 185 van de Landsregeling de mogelijkheid de Eilandenregeling bij landsverordening te wijzigen, mits deze met de stemmen van twee derden van het wettelijk aantal leden door de Staten is goedgekeurd en na goedkeuring door de Koning.

$\mathrm{Al}$ is de Eilandenregeling bij A.M.v.B. vastgesteld, niettemin hebben van de aanvang af Antilliaanse krachten meegewerkt. Reeds dadelijk bij de samenstelling van het voor-ontwerp, vervolgens in de vorm van een rapport van een Antilliaanse financiële commissie en een rapport van een ambtelijk werkbureau. De Staten brachten in October 1950 een constructief advies op het ontwerp uit en tenslotte heeft de Vice-Minister-President, $\mathrm{Mr}$ J. R. H. vAN SchaIK, vergezeld van enige ambtenaren, op Curaçao en Aruba omstandig overleg gepleegd, dat tot volledige overeenstemming heeft geleid, behoudens ten aanzien van een enkel punt: de benoeming van de gezaghebbers door de Kroon zonder overleg met regeringsraad of eilandsraden.

Enkele Arubanen verwijten de Regering, dat de Eilandenregeling minder geeft dan het rapport van de Commissie Aruba-Curaçao (vaak naar de voorzitter als rapport-VAN POELJE aangeduid) en dat men onnodig van het daarbij gevoegde ontwerp van een landsgrondwet is afgeweken. Bepaald ten onrechte. Het rapport heeft als basis gediend voor de Eilandenregeling. Elk artikel dat overgenomen kon worden, is overgenomen. Alle artikelen konden echter niet worden ingepast, omdat het rapport uit ging van de toenmaals levende gedachte, dat krachtens een rijksgrondwet ieder gebiedsdeel een eigen landsgrondwet zou vaststellen. De ontwikkeling heeft echter een ander verloop genomen.

Voorafgaande aan een definitieve regeling is een Interimregeling tot stand gekomen, waarbij aan de Nederlandse Antillen autonomie is verleend. Daarbij is van de gelegenheid gebruik gemaakt in de Landsregeling in een afzonderlijk hoofdstuk de hoofdbeginselen voor de zelfstandigheid der eilanden op te nemen. Door de handhaving van de Staatsregeling (thans Landsregeling geheten) zijn verschillende artikelen van het ontwerp-vaN POELJE, welke noodzakelijk zouden zijn, indien de Staatsregeling was komen te vervallen, niet meer aan de orde. Met alle 
hoofdbeginselen van het ontwerp-van PoELJE is echter terdege rekening gehouden.

Welke zijn de hoofdgedachten van de Eilandenregeling?

Zij zijn - gelijk gezegd - neergelegd in het Vijfde Hoofdstuk van de Landsregeling en in de Eilandenregeling nader uitgewerkt.

In de eerste plaats hebben de vier eilandgebieden eigen organen gekregen voor de behartiging van de eigen aangelegenheden. Deze organen zijn: de eilandsraad, het bestuurscollege en de gezaghebber.

De gekozen eilandsraad op Aruba en op Curaçao telt 21 leden. Aan de eilandsraad behoort alle bevoegdheid met betrekking tot de regeling en het bestuur van de eigen aangelegenheden, voorzover zij niet aan de gezaghebber of het bestuurscollege is opgedragen. Deze ruim gestelde redactie geeft duidelijk de invloedrijke positie van de raad aan. De gebruikelijke bepalingen omtrent de vereisten van het lidmaatschap, de orde der vergaderingen, enz. kunnen hier onvermeld blijven.

Het bestuurscollege bestaat uit de gezaghebber en tenminste twee en ten hoogste vier gedeputeerden. De gedeputeerden worden voor de gehele zittingsduur van de eilandsraad, d.i. vier jaren, door de eilandsraad al dan niet uit zijn midden gekozen. Om de gedachten te bepalen zouden wij kunnen zeggen, dat het college het dagelijks bestuur voert. Van hetgeen daartoe onder meer behoort, wordt een uitvoerige opsomming gegeven. Wij noemen thans alleen: het voorbereiden en uitvoeren van de besluiten van de raad, het beheer van inkomsten en uitgaven, het onderhoud en toezicht op velerlei werken, het vaststellen van eilandsbesluiten houdende algemene maatregelen.

Het bestuurscollege is voor zijn beleid verantwoording verschuldigd aan de eilandsraad. Zijn leden verstrekken alle door de raad verlangde inlichtingen.

De gezaghebber wordt door de Koning (voor zes jaren) benoemd en ontslagen. Hij is de centrale figuur, de voorzitter in beide eilandscolleges (in de eilandsraad met adviserende stem), plaatselijk hoofd van de politie. Hij staat de landsregering bij in de uitvoering van de landstaak en werkt mee aan de uitvoering van de taak van de Gouverneur als orgaan van het Koninkrijk. Hij kan dan ook om het hoger toezicht tot zijn recht te doen komen, steeds als hij vermeent dat een eilandsverordening of een eilandsbesluit in strijd is met enig wettelijk voorschrift, de werking daarvan voorkomen, of opschorten tot een hogere instantie ter zake een 
beslissing heeft genomen. Deze hogere instantie is de landsregering, indien het betreft strijd met een landsverordening of een landsbesluit, houdende algemene maatregelen, dan wel met het algemeen belang van de Nederlandse Antillen; en het is de Gouverneur als orgaan van het Koninkrijk, indien het betreft strijd met hogere wettelijke regelingen dan wel met het algemeen belang van het Koninkrijk.

In de tweede plaats hebben de eilandgebieden eigen geldmiddelen. Het uitgangspunt was dat de opbrengst van alle belastingen en retributies aan de eilanden toekomt en dat zij volle vrijheid hebben belastingen in te stellen. Van deze volledige belastingvrijheid moest om twee redenen worden afgeweken.

Het is nl. gewenst, dat de Nederlandse Antillen voor de centrale huishouding kan beschikken over gelden verkregen uit eigen middelen. Op grond van die overweging zijn de in- en uitvoerrechten en accijnzen, de zegel- en registratierechten, zomede retributies voor diensten door de Nederlandse Antillen bewezen, als eigen middelen voor de Nederlandse Antillen gereserveerd. Op deze wijze vloeien vermoedelijk voldoende middelen regelmatig binnen.

Zo eenvoudig als deze oplossing lijkt, is zij echter niet. Het is immers zeer wel mogelijk, dat het aandeel door ingezetenen van Aruba in de in- en uitvoerrechten en accijnzen opgebracht groter is dan het eiland redelijkerwijze in de algemene bestuurskosten zou behoeven bij te dragen. Meer betalen dan redelijkerwijze nodig is, staat Aruba niet aan. Curaçao evenmin. Het was der-' halve nodig te bepalen dat jaarlijks zal worden becijferd welk deel in de opbrengst van de in- en uitvoerrechten en accijnzen van Aruba afkomstig is en welk deel van Curaçao. Vervolgens welk percentage redelijk was te achten en het verschil te verrekenen. Aldus wordt in de Eilandenregeling getracht de lieve vrede te bewaren. De voor de berekening vereiste algebraïsche formule worde $\mathrm{u}$ bespaard. Het getal inwoners van Aruba en van Curaçao geldt als factor en ook het getal guldens der middelen van Aruba en van Curaçao. Deze zelfde algebraïsche formule dient eveneens in het geval de eigen middelen van de Nederlandse Antillen niet voldoende zijn om de kosten van de centrale huishouding te dekken. Aruba en Curaçao zijn dan gehouden het ontbrekende bij te dragen in de verhouding als door de formule wordt aangegeven. Voor ieder dienstjaar heeft deze berekening plaats.

De tweede reden voor afwijking van het beginsel der volledige 
belastingvrijheid is van praktische aard om moeilijkheden te vermijden, welke zouden rijzen indien ieder gebiedsdeel zijn eigen wetgeving vaststelde en de aanslagen zou opleggen betreffende de inkomstenbelasting, de winstbelasting, de grondbelasting, de gebruiksbelasting en het successie- en schenkingsrecht. Dubbele belastingheffing zou alsdan moeilijk te vermijden zijn. Om die reden is bepaald, dat de wetgeving inzake en de oplegging van de aanslagen in de genoemde kohierbelastingen door de Nederlandse Antillen geschieden. De verdeling van de opbrengst zal geschieden volgens normen bij landsverordening aan te geven.

De voorbereidende werkzaamheden verbonden aan de overdracht van het financiëel beheer en het belastingwezen zijn zo omvangrijk, dat deze gesteld is op 1 Januari 1953. Tot die datum worden aan de eilandgebieden de op de Antillaanse begroting uitgetrokken bedragen voor de overgedragen diensten aan de eilandgebieden in beheer gegeven.

In de derde plaats hebben de eilandgebieden een eigen taak.

Het is duidelijk, dat al hetgeen volgens de Interimregeling bij wet of algemene maatregel van bestuur moet of kan geschieden, niet aan de eilandgebieden kan worden overgedragen. Hetzelfde geldt voor hetgeen uitdrukkelijk in de Landsregeling of de Eilandenregeling aan de landsverordening is opgedragen, behoudens enige in bepaalde artikelen genoemde werkzaamheden bv. pacht van domaniale gronden, toezicht op het armenwezen en op het vervoerwezen.

De Eilandenregeling geeft aan welke aangelegenheden overigens niet tot de zorg van een eilandgebied behoren. Behalve de reeds vermelde taakverdeling op het belastinggebied worden twee groepen van onderwerpen onderscheiden. De eerste groep omvat de onderwerpen, welke hetzij met het oog op het landsbelang, hetzij uit overwegingen van internationale aard niet voor overdracht aan de eilandgebieden in aanmerking komen. Deze zijn: het burgerlijk- en handelsrecht, strafrecht enz., het politiewezen, de posterijen enz.; het verkeer tussen de eilandgebieden, de arbeidswetgeving, de meteorologische dienst, de vaststelling van minimum tarieven voor loodsgelden en voor gebruik van vliegvelden en de toelating, vestiging en uitzetting. Dat ten aanzien van deze onderwerpen eenheid in wetgeving en uitvoering in de Nederlandse Antillen dient te bestaan, zal wel vanzelfsprekend geoordeeld worden. 
De tweede groep omvat de onderwerpen, waarvan de regeling niet tot de zorg van een eilandgebied behoort, doch ten aanzien waarvan bij landsverordening of landsbesluit uitvoerende bevoegdheden worden toegekend aan organen en diensten van de eilandgebieden, voorzover dit doelmatig is. In het kort gezegd: wel eenheid in de wetgeving, doch - indien doelmatig - de uitvoering over te laten aan de plaatselijke organen. Wij noemen hiervan: het gevangeniswezen, de gezondheidszorg, de onderwijsorganisatie (voor zover voorwerp van zorg der landsregering).

Alle aangelegenheden niet tot de bovengenoemde groepen behorende, zullen mitsdien tot de zorg van de eilandgebieden behoren en door de landsregering aan de eilandgebieden moeten worden overgedragen.

Het zal de aandachtige lezer zijn opgevallen, dat tot nu toe bij de uiteenzetting over de hoofdgedachten van de Eilandenregeling uitsluitend Aruba en Curaçao zijn ter sprake gekomen. De reden daarvan is, dat ook in de Eilandenregeling de uitvoerige behandeling van de eilandsorganen en hunne bevoegdheden alleen op Aruba en Curaçao betrekking heeft. Daarna volgen twee afzonderlijke titels onderscheidenlijk op Bonaire en de Bovenwindse Eilanden betrekking hebbende. Die titels konden beknopt zijn, omdat de algemene gedragslijn is, dat alle voor Aruba en Curaçao geldende bepalingen van overeenkomstige toepassing zijn voor Bonaire en de Bovenwindse Eilanden, behoudens voorzover daarvan in deze titels wordt afgeweken. De afwijkingen vinden uitsluitend hun grond in de geringere bevolkingssterkte en geringerè draagkracht van beide eilandgebieden en voor de Bovenwindse Eilanden bovendien in het feit dat het eilandgebied bestaat uit drie eilanden zonder gemakkelijke verbinding. De afwijkingen voor Bonaire bestaan in een kleiner ledental van de eilandsraad, nl. zeven of hoogstens negen; uit een kleiner aantal gedeputeerden nl. twee, uit de verenigbaarheid van de functies van Gezaghebber en secretaris en uit een andere vaststelling van de begroting. Indien nl. de begroting met een nadelig saldo sluit, kan de eilandsraad de begroting niet zelf alleen vaststellen buiten de landsorganen om. Het nadelig saldo wordt nl. door de Nederlandse Antillen betaald; dit nadelig saldo maakt deel uit van de algemene bestuurskosten der Nederlandse Antillen, welke in feite grotendeels door Aruba en Curaçao worden gedragen.

Het is mitsdien redelijk, dat bij landsverordening bepaald wordt of het nadelig saldo geheel wordt goedgekeurd. De lands- 
verordening mag het nadelig saldo echter niet zo zeer reduceren, dat het eilandgebied niet meer in staat zou zijn het bestuursapparaat normaal te doen functionneren en redelijke voorzieningen te treffen. Bij A.M.v.B. kunnen daaromtrent nadere regels worden gesteld.

De bepalingen betreffende de onderlinge verrekening van Aruba en Curaçao en die betreffende de dekking van de algemene bestuurskosten van de Nederlandse Antillen zijn niet op Bonaire van toepassing; ook kan Bonaire geen lening aangaan.

De afwijkingen voor Bonaire gelden in het algemeen ook voor de Bovenwindse Eilanden, echter niet die betreffende het aantal leden van de eilandsraad en het aantal gedeputeerden. Met het oog op de moeilijke verbindingen tussen de eilanden is nl. de regeling getroffen, dat de leden voor ieder eiland gekozen als een afzonderlijke afdeling van de eilandsraad kunnen vergaderen en besluiten. Elke afdeling bestaat uit vijf leden, de eilandsraad mitsdien uit vijftien. Om diezelfde reden kiest elke afdeling twee gedeputeerden en het eilandgebied zes gedeputeerden. Zoveel mogelijk hebben de afdelingen en de daarbij betrokken gedeputeerden gelijke bevoegdheden voor hun eigen gebied als de eilandsraad en de gedeputeerden voor het gehele eilandgebied. De gezaghebber heeft standplaats op St. Maarten; zijn taak oefent hij op Saba en St. Eustatius uit door middel van administrateurs.

\section{DE UITVOERING VAN DE EILANDENREGELING}

Het ligt voor de hand, dat met de inwerkingtreding van de Eilandenregeling op 14 Maart 1951 de taak van de eilandgebieden nog niet in haar geheel konden worden overgedragen. Eerst moesten verkiezingen voor de eilandsraden worden gehouden; dit geschiedde op 4 Juni 1951.

Van het resultaat delen wij alleen een note gaie mede: Aruba heeft de 8-8 verhouding behouden, doch in haar eilandsraad: de beide grootste partijen hebben elk acht zetels! De installatie had plaats op 2 Juli en op die dag of kort daarna werden op Curaçao vier gedeputeerden, op Aruba voorlopig twee, op Bonaire twee en op de Bovenwindse Eilanden zes gedeputeerden verkozen.

-Op 6 September ging de eerste dienst, die van Openbare Werken over. Wanneer volgen de overige? In de overgangsbepalingen van de Eilandenregeling wordt gerekend dat de verdere overdracht zich zal kunnen voltrekken in de loop van 1952 en dat op 1 
Januari 1953 de financiële overdracht zal zijn voltrokken. In 1953 en volgende jaren zal dan door de eilandgebieden gewerkt worden op de door hen zelf vastgestelde begrotingen en met eigen middelen.

De overdracht wordt telkens bij landsverordening geregeld. Dienst voor dienst moet worden overwogen of deze voor gehele of gedeeltelijke overdracht in aanmerking komt en op welk tijdstip. Blijkt tenslotte hetgeen niet is overgedragen niet overeen te stemmen met hetgeen de Eilandenregeling niet aan de eilandgebieden toedacht, dan zal de vraag aan de orde komen of de Eilandenregeling al dan niet moet worden gewijzigd. De praktijk zal dan een krachtig woord kunnen meespreken en de argumenten voor en tegen een bepaalde overdracht zullen beter dan thans kunnen worden overzien.

Om aan dit tijdschema te kunnen voldoen, zal de overdracht met voortvarendheid dienen te worden voorbereid, want er zijn inderdaad moeilijkheden van personele, technische en wetgevende aard te overwinnen. Dit laatste wordt niet altijd voldoende begrepen en terecht of ten onrechte wordt de vertraagde voortgang aan onwil en opzet geweten. Het is inderdaad menselijk en het is in soortgelijke gevallen herhaaldelijk voorgekomen, dat een centraal gezag, een centrale dienst niet gemakkelijk een deel van haar macht en taak aan lagere organen overdraagt.

Ook is het verwijt geuit, dat het landsbelang bij het partijbelang wordt achtergesteld. Het partijbelang zou namelijk bij handhaving van de status quo gebaat kunnen zijn als een partij in de Staten groter invloed heeft dan in de eilandsraad.

Hoe het zij, tot driemaal toe zijn onderhandelingen om een geroutineerde kracht uit Nederland voor het voorbereidende werk te doen overkomen, op het laatste ogenblik van Antilliaanse zijde afgesneden.

Stellig vertragend werken in ieder geval de politieke wrijvingen in de Antillen: de langdurige formatie bij wisselingen van Regeringsraad, de herhaalde obstructie door het ontbreken van het quorum voor een Statenvergadering, de onzakelijke debatten. Dit alles heeft een verlammende invloed op de werkzaamheden van de Staten en van de Regeringsraad. De laatste begrotingen werden dan ook veel te laat vastgesteld; de Antilliaanse Interimregeling kwam negen maanden later tot stand dan die van Suriname; het advies op de Eilandenregeling vereiste ruim vijf en een halve maand. En wist U, dat het aantalin de Staten afgehandelde verordeningen (buiten de begrotingen) in de jaren 1947, 
1948 en 1949 onderscheidenlijk 33, 38 en 39 bedroeg, doch in 1950 slechts 18 en in het eerste half jaar 1951 niet meer dan 7?

Het was dan ook goed gezien, dat velerlei wetgevende arbeid van de eilandgebieden voor de eerste maal aan landsbesluiten, houdende algemene maatregelen, en niet aan landsverordeningen werd overgelaten.

Ook al zouden de bovenvermelde veronderstellingen ten onrechte geuit zijn, het is te hopen, dat de overdracht zo krachtig wordt voortgezet, dat de eilandgebieden het centraal gezag niet kunnen verwijten aan haar te onthouden hetgeen de Eilandenregeling haar toedacht.

Nov. 1951

\section{SUMMARY}

\section{THE INDEPENDENCE OF THE ISLANDS OF THE NETHERLANDS ANTILLES}

The Netherlands Antilles - consisting of the islands of Curaçao, Aruba and Bonaire (Leeward Group), all lying close to the South American mainland, and to the north the very small islands of St. Martin (partly French, the Dutch part called Sint Maarten), St. Eustatius (Statia) and Saba (Windward Group) - had a central administration for more than a century.

In September 1950 an interim settlement for the Antilles was reached, which conferred complete autonomy on this territory. After the War Aruba expressed the wish to be independant of Curaçao and to enter into a direct relation with the Netherlands. In order to meet this wish as far as might be considered reasonable, extensive and thorough negotiations took place resulting in a settlement for the Antilles in which a very large measure of independence, within the whole of the Netherlands Antilles, was granted to each island or "island territory". The three smaller islands of the Windward Group were considered to form one "island territory". The underlying principle was that the islands would get:

I. their own organs for their internal affairs,

2. their own finances,

3. a competence of their own.

I. Their own organs are the elected island council, which has complete authority as far as it has not been assigned to the other organs; the administrative board consisting of the administrator and of two to four deputies, which looks after daily affairs and is responsible to the island council; the administrator appointed by the Crown, who is the central figure, chairman of the two bodies mentioned above and local chief of police. He can call in central supervision by eliciting a decision from the central government, if one of the insular bodies acts in defiance of statutory regulations or against the general interests of the Netherlands 
Antilles, and in eliciting a decision from the Governor representing the Kingdom, if one of the insular bodies acts in defiance of statutory regulations of a higher order or against the general interests of the Kingdom.

2. The islands obtain their own finances by raising taxes. Only a few expressly mentioned levies, e.g. import and export duties, are reserved for the Netherlands Antilles to defray the expenses of the central administration. If the proceeds of these duties should be insufficient, Aruba and Curaçao will be obliged to pay the balance in proportion to their financial capacity and population figures.

3. The underlying principle is that everything will belong to the competence of the islands. This principle has been limited in two ways: expressly mentioned are matters, which either in view of the interests of the country or on account of considerations on the international plane, cannot be assigned to the islands, neither legislatively nor executively. Secondly matters are mentioned, the legislation of which does not belong to the competence of island territories, but of which the executive powers may be assigned to insular bodies, if this should make for efficiency.

Completely the same arrangement obtains for the smaller territories of Bonaire and the Windward Group, except for some deviations on account of smaller population and financial capacity.

The Islands Settlement became effective on the 14th of March 1951. Elections were held as soon as possible and deputies appointed. At the beginning of September the first public service, the Public Works Department, was handed over. In the course of 1952 the other services will follow and on the 1st of January 1953 the transference of the Finance Department will be completed, so that from then onward the islands will work with their own budgets and revenues.

Helsdingen, W. H. van: De Eilandenregeling Nederlandse Antillen met toelichting. 's-Gravenhage, 1951, $121 \mathrm{blz}$.

De gedachte dat het zijn nut zou kunnen hebben - voor hen die met de Eilandenregeling in de praktijk te maken hebben - om kennis te nemen van de wordingsgeschiedenis der artikelen, heeft mr vaN HeLsDingen tot de samenstelling van deze toelichting gebracht. De tekst betreffende de Eilandsraad en het Bestuurscollege is van de hand van mr P. G. Hooghoudr. Het is een aantrekkelijk boekje geworden, dat bij het Ministerie voor Uniezaken en Overzeese Rijksdelen kan worden aangevraagd.

Red. 